\title{
Clinical significance of colonic intraepithelial lymphocytosis in a pediatric population
}

\author{
Robert M Najarian ${ }^{1}$, Elizabeth J Hait ${ }^{2}$, Alan M Leichtner ${ }^{2}$, Jonathan N Glickman ${ }^{3,4}$, \\ Donald A Antonioli ${ }^{1,3}$ and Jeffrey D Goldsmith ${ }^{1,3}$
}

${ }^{1}$ Department of Pathology, Beth Israel Deaconess Medical Center and Harvard Medical School, Boston, MA, USA; ${ }^{2}$ Division of Gastroenterology and Nutrition, Children's Hospital Boston and Harvard Medical School, Boston, MA, USA; ${ }^{3}$ Department of Pathology, Children's Hospital Boston and Harvard Medical School, Boston, MA, USA and ${ }^{4}$ Department of Pathology, Brigham and Women's Hospital and Harvard Medical School, Boston, MA, USA

\begin{abstract}
The significance of colonic intraepithelial lymphocytosis has been well described in adults, and is associated with lymphocytic colitis, untreated celiac disease, and medications, among others. Little is known about the meaning of colonic intraepithelial lymphocytosis in the pediatric population; this study examines this finding in a cohort of children. Twenty patients in whom colonic intraepithelial lymphocytosis was a prominent feature were identified from 1999 to 2005. Colonic intraepithelial lymphocytosis was defined as 20 or more intraepithelial lymphocytes per 100 colonocytes present in at least one colonic mucosal biopsy. Each biopsy was examined for numbers of intraepithelial lymphocytes per 100 surface and crypt colonocytes; various architectural, inflammatory, and metaplastic changes were also noted. When available, concurrent duodenal and/or ileal biopsies were examined. Studied clinical parameters included indications for biopsy, clinical followup, final diagnosis, comorbidities, autoimmune serologies, and medications. A total of 121 colonic mucosal biopsies were examined in 20 patients who ranged from 1 to 17 years (mean 10.2 years; $40 \%$ male). Common indications for endoscopy included diarrhea and abdominal pain. A mean of $29( \pm 22)$ intraepithelial lymphocytes per 100 enterocytes were seen. Seven patients had colonic intraepithelial lymphocytosis as the only histologic finding. The remaining 13 patients had additional architectural, inflammatory, and metaplastic changes. The mean follow-up period was 14 months (range 1-48 months). Inflammatory bowel disease was diagnosed in 4 of 20 patients and was seen chiefly in biopsies in which colonic intraepithelial lymphocytosis was associated with architectural or inflammatory changes. Common disease associations include celiac disease, lymphocytic colitis, and autoimmune enteropathy. Pediatric colonic intraepithelial lymphocytosis, in the absence of other histologic findings, is associated with various diseases, including celiac disease, lymphocytic colitis, and autoimmune enteropathy. Colonic intraepithelial lymphocytosis in the presence of other inflammatory changes indicates the possibility of idiopathic inflammatory bowel disease. These findings are similar to those seen in adults, with the exception of autoimmune enteropathy.
\end{abstract}

Modern Pathology (2009) 22, 13-20; doi:10.1038/modpathol.2008.139; published online 5 September 2008

Keywords: intraepithelial lymphocytosis; pediatric; inflammatory bowel disease; celiac disease; lymphocytic colitis

The presence of increased numbers of mucosal intraepithelial lymphocytes within the luminal gastrointestinal tract is a pattern of injury that evokes an extensive differential diagnosis based on the site of injury and other associated histologic findings. In the small intestine, the significance of

Correspondence: Dr JD Goldsmith, Department of Pathology, Beth Israel Deaconess Medical Center, 330 Brookline Avenue, Boston, MA 02215, USA.

E-mail: jgoldsmi@bidmc.harvard.edu

The contents of this paper were presented at the 2007 annual meeting of The United States and Canadian Academy of Pathology, San Diego, CA, USA.

Received 13 June 2008; revised 5 August 2008; accepted 6 August 2008; published online 5 September 2008 intraepithelial lymphocytosis has been well studied in pediatric and adult populations, and raises a differential diagnosis that includes celiac disease, food/protein intolerance, Crohn's disease, and various infections. ${ }^{1-4}$

The clinicopathologic significance of colonic intraepithelial lymphocytosis in the adult is well understood. When present in colonic biopsies in adults, increased intraepithelial lymphocytes, in the absence of other architectural or inflammatory changes, calls forth a differential diagnosis that includes lymphocytic colitis, collagenous colitis, and drug-induced colitis. ${ }^{5,6}$ Colonic intraepithelial lymphocytosis can also be seen in patients with untreated celiac disease that represents a widespread 
response to gluten-mediated injury. ${ }^{7}$ Little is known, however, about the significance of colonic intraepithelial lymphocytosis in the pediatric population, and no studies to date have reported on the spectrum of diseases associated with this finding in a large cohort of young patients.

Through the use of clinical follow-up data in a population of symptomatic pediatric patients presenting for colonoscopy and biopsy, our aim was to determine the clinical significance of increased numbers of colonic intraepithelial lymphocytes either as the sole histologic finding or in association with other architectural/inflammatory changes.

\section{Materials and methods}

The patient cohort was obtained by searching the laboratory information system of the surgical pathology laboratory at Children's Hospital Boston for 'intraepithelial lymphocytes' and 'colon' from 1999 to 2005. In addition, the total number of endoscopic procedures was estimated by searching the endoscopy database during the same period. In the resultant biopsies, the mean number of intraepithelial lymphocytes per 100 colonocytes was counted by two of the authors (RMN and JDG) for each biopsy; the mean number of intraepithelial lymphocytes per 100 colonocytes was used as the final intraepithelial lymphocyte count. Separate values were obtained for surface and crypt intraepithelial lymphocytes; the minimal number of intraepithelial lymphocytes required for inclusion in the study was 20 intraepithelial lymphocytes per 100 colonocytes. Two separate high-power fields in each biopsy ( $\times 400$ magnification) that showed the highest density of intraepithelial lymphocytes were selected for formal counts. When available, biopsies of the duodenum and terminal ileum were also reviewed and intraepithelial lymphocytes and relevant histologic findings noted; intraepithelial lymphocytes were not counted in ileal biopsies that contained numerous lymphoid aggregates, nor were intraepithelial lymphocytes counted above or adjacent to lymphoid aggregates in colonic biopsies. Gastric mucosal biopsies were available in a minority of cases and thus were not reviewed. In all cases, biopsies were reviewed by two study pathologists (RMN and JDG), who were blinded to the indication for biopsy and clinical history.

The biopsies were in addition evaluated for the presence of other histopathologic findings, including the presence of basal lymphoid aggregates and plasma cells (clusters of 20 or more lymphocytes and/or plasma cells within the basal one-third of the colonic mucosa), ulceration, crypt architectural distortion, basal plasmacytosis (plasma cells present between the muscularis mucosae and the basal aspects of the colonic crypts), neutrophilic cryptitis (neutrophils within the colonic epithelium), crypt abscesses (clusters of five or more neutrophils within crypt lumina), increased lamina propria lymphocytes, and/or plasma cells that expanded the lamina propria, granulomas, Paneth cells present in the distal one-half of the colon, the presence of a thickened subepithelial collagen layer, pyloric gland metaplasia of crypt epithelium, the presence of crypt epithelial apoptotic debris, surface epithelial damage (decreased amounts of colonic epithelial cytoplasm with concomitantly increased nuclear size), epithelial denudation, increased lamina propria eosinophils that expanded the lamina propria, and clusters of intraepithelial eosinophils.

On completion of the biopsy review, the study patients' clinical information, including biopsy indication, medical comorbidities, current drug regimens, and autoimmune serologies, were provided by two other study authors (EH and $\mathrm{AL}$ ). In addition, the final clinical diagnoses, as well as clinical follow-up and further biopsy findings, were reviewed at this time to establish any salient associations.

\section{Results}

\section{Patient Characteristics}

The study cohort was composed of 20 patients who underwent a total of 121 colonic mucosal biopsies. Over the study period, endoscopies were performed on approximately 2450 patients for an estimated incidence of $0.8 \%$ over the 7 -year-study period. The mean patient age was 10.2 years (range 1-17 years); $40 \%$ of the patients were male. Demographic characteristics including patient age and sex, indications for biopsy, medical comorbidities, and medications are summarized in Table 1. The most common indications for endoscopy and biopsy were diarrhea (six patients), abdominal pain (four patients), and a combination of abdominal pain and diarrhea (six patients). Twelve patients were taking various medications at initial presentation (Table 1); there were no common medications, with the exceptions of insulin and proton-pump inhibitors, among the study patients.

Coexistent medical comorbidities were found in 12 patients (Table 1). Seven patients had autoimmune diseases including two patients each with primary sclerosing cholangitis and insulin-dependent diabetes mellitus, and one patient each with hypothyroidism and multisystem autoimmune disease. Also, one patient (no. 20) had the coexistence of idiopathic thrombocytopenic purpura and autoimmune hemolytic anemia. In addition, three patients had documented infectious disease at presentation, including one with Helicobacter pylori gastritis (diagnosed with $H$. pylori antibody testing), one with enterobiasis, and one with rotavirus infection. One other patient was known to have common variable immunodeficiency. Finally, three patients were noted to have medical comorbidities that were likely unrelated to their presentation for 
Table 1 Patient demographics, past medical histories, and medications

\begin{tabular}{|c|c|c|c|c|c|}
\hline Case & Age (years) & $M / F$ & Biopsy indications & Medical comorbidities & Medications \\
\hline 1 & 9 & $\mathrm{~F}$ & Abdominal pain & None & Lactulose \\
\hline 2 & 1 & M & Diarrhea & Rotavirus infection & $\begin{array}{l}\text { Prednisolone, prilosec, } \\
\text { 6-mercaptopurine }\end{array}$ \\
\hline 3 & 9 & $\mathrm{M}$ & Diarrhea & $\begin{array}{l}\text { Type I diabetes, severe } \\
\text { multisystem autoimmune } \\
\text { disease/autoimmune } \\
\text { enteropathy }\end{array}$ & Insulin, prilosec, rituximab \\
\hline 4 & 4 & $\mathrm{M}$ & Dilated colon & $\begin{array}{l}\text { s/p colostomy for } \\
\text { Hirschprung's disease }\end{array}$ & Miralax \\
\hline 5 & 15 & $\mathrm{~F}$ & Abdominal pain & $\begin{array}{l}\text { Peripheral eosinophilia, } \\
\text { elevated IgE }\end{array}$ & $\begin{array}{l}\text { Clarithromycin, amoxicillin, } \\
\text { bismuth subsalicylate, } \\
\text { omeprezole for H. pylori }\end{array}$ \\
\hline 6 & 7 & $\mathrm{~F}$ & Diarrhea, abdominal pain & None & None \\
\hline 7 & 16 & $\mathrm{~F}$ & Diarrhea, abdominal pain & Hypercholesterolemia & Metronidazole \\
\hline 8 & 16 & $\mathrm{M}$ & Perianal abscess & None & None \\
\hline 9 & 10 & $\mathrm{~F}$ & Abdominal pain, diarrhea & $\begin{array}{l}\text { Primary sclerosing } \\
\text { cholangitis }\end{array}$ & None \\
\hline 10 & 12 & $\mathrm{M}$ & $\begin{array}{l}\text { Weight loss, abdominal } \\
\text { pain, diarrhea }\end{array}$ & None & None \\
\hline 11 & 8 & $\mathrm{~F}$ & Rectal bleeding & $\begin{array}{l}\text { Primary sclerosing } \\
\text { cholangitis }\end{array}$ & None \\
\hline 12 & 14 & $\mathrm{~F}$ & $\begin{array}{l}\text { Weight loss, abdominal } \\
\text { pain, diarrhea }\end{array}$ & H. pylori Ab positive & Isoniazid \\
\hline 13 & 10 & $\mathrm{~F}$ & $\begin{array}{l}\text { Abdominal pain, oral } \\
\text { ulcers }\end{array}$ & None & Prevacid, miralax \\
\hline 14 & 17 & $\mathrm{~F}$ & $\begin{array}{l}\text { Abdominal pain, rectal } \\
\text { bleeding }\end{array}$ & None & Lactaid \\
\hline 15 & 2 & $\mathrm{M}$ & Diarrhea & Chiari malformation & None \\
\hline 16 & 15 & $\mathrm{~F}$ & $\begin{array}{l}\text { Perianal fistula, rectal } \\
\text { bleeding }\end{array}$ & Type I diabetes, enterobiasis & IV insulin, ceftriaxone \\
\hline 17 & 3 & $\mathrm{~F}$ & Diarrhea, weight loss & None & None \\
\hline 18 & 17 & $\mathrm{M}$ & Abdominal pain, diarrhea & Schizoaffective disorder & Cogentin, depakote, abilify \\
\hline 19 & 1 & $\mathrm{~F}$ & Vomiting, diarrhea & Hypothyroidism & None \\
\hline 20 & 16 & M & Diarrhea & $\begin{array}{l}\text { CVID, ITP, autoimmune } \\
\text { hemolytic anemia, } \\
\text { lymphoproliferative disorder }\end{array}$ & $\begin{array}{l}\text { Pencillin, nexium, bactrim, } \\
\text { morphine, solumedrol, } \\
\text { pamidronate, ketorolac, IVIG }\end{array}$ \\
\hline
\end{tabular}

CVID, common variable immunodeficiency; F, female; ITP, idiopathic thrombocytopenic purpura; IVIG, intravenous immunoglobulin; M, male.

colonic biopsy including hypercholesterolemia, Chiari malformation, and schizoaffective disorder each present in one patient.

\section{Histopathology}

The histopathologic findings are presented in Table 2. The mean intraepithelial lymphocyte count in all biopsies was 29 intraepithelial lymphocytes per 100 enterocytes (range \pm 22 ). A total of 13 patients showed an increase in mean intraepithelial lymphocytes exclusively within the surface epithelium (mean $34 \pm 17$ intraepithelial lymphocytes per 100 colonocytes), whereas 3 patients showed increased mean intraepithelial lymphocytes within both the crypt and surface compartments (surface intraepithelial lymphocytes: mean $63 \pm 12$ per 100 colonocytes; crypt intraepithelial lymphocytes: mean $32 \pm 9$ per 100 colonocytes); these 3 patients were later classified as having lymphocytic colitis. One patient who had two sets of evaluable biopsies was found to have crypt intraepithelial lymphocytosis (22 \pm 5 per 100 colonocytes), without increases in surface intraepithelial lymphocytes, and was ultimately diagnosed with autoimmune enteropathy (patient 2). Three patients were found to have mean intraepithelial lymphocyte counts of less than 20 lymphocytes per 100 colonocytes when averaging counts from multiple biopsies, but were included in this study because colonic intraepithelial lymphocytosis was observed in at least one of the biopsy samples. Two of these patients had colonic intraepithelial lymphocytosis isolated to the epithelial surface, whereas one patient had colonic intraepithelial lymphocytosis of both the surface and crypt components. In all cases, multiple colonic biopsies (mean of 5.4 biopsies per patient, range 2-9 biopsies) were available for review and revealed that no patients had increased intraepithelial lymphocytes that were preferentially present in either the right or left colon. In addition, $2(10 \%)$ of the patients had colonic intraepithelial lymphocytosis present in only one biopsy, and the remaining 18 $(90 \%)$ of the patients had colonic intraepithelial lymphocytosis present in two or more biopsies.

Although colonic intraepithelial lymphocytosis was the sole histologic finding in seven patients (Figure 1), thirteen patients had other inflammatory/ architectural findings (see Table 2). Additional 
Table 2 Salient histopathologic findings

\begin{tabular}{|c|c|c|c|c|}
\hline Case & $\begin{array}{l}\text { Surface IELs } \\
\text { mean (range) }\end{array}$ & $\begin{array}{l}\text { Crypt IELs mean } \\
\text { (range) }\end{array}$ & $\begin{array}{l}\text { Additional histologic findings } \\
\text { in colon }\end{array}$ & Final clinical diagnosis \\
\hline 1 & $26(12-42)$ & $11(7-18)$ & None & Constipation \\
\hline 2 & $11(7-18)$ & $22(17-25)$ & $\begin{array}{l}\text { Cryptitis, basal lymphoid } \\
\text { aggregates, surface ulceration, } \\
\text { epithelial damage }\end{array}$ & Autoimmune enteropathy \\
\hline 3 & $32(26-35)$ & $18(17-20)$ & $\begin{array}{l}\text { Marked epithelial damage, } \\
\text { architectural distortion, } \\
\text { increased apoptotic debris, } \\
\text { increased lamina propria CI }\end{array}$ & $\begin{array}{l}\text { Severe multisystem autoimmune } \\
\text { disease with autoimmune } \\
\text { enteropathy }\end{array}$ \\
\hline 4 & $21(8-30)$ & $12(8-17)$ & None & Hirschprung's disease \\
\hline 5 & $20(11-31)$ & $14(10-17)$ & None & Allergic colitis \\
\hline 6 & $77(51-126)$ & $27(18-34)$ & None & Lymphocytic colitis \\
\hline 7 & $38(10-105)$ & $17(6-31)$ & Paneth cell metaplasia & Healing $C$. difficile colitis \\
\hline 8 & $26(5-60)$ & $14(9-20)$ & Epithelial denudation & Perianal abscess \\
\hline $9^{a}$ & $16(11-20)$ & $11(5-20)$ & $\begin{array}{l}\text { Cryptitis, crypt abscesses, } \\
\text { architectural distortion, basal } \\
\text { lymphoid aggregates, increased } \\
\text { lamina propria CI }\end{array}$ & Ulcerative colitis \\
\hline 10 & $23(6-49)$ & $8(4-13)$ & None & Crohn's disease \\
\hline 11 & $31(10-61)$ & $12(3-22)$ & $\begin{array}{l}\text { Cryptitis, crypt abscesses, } \\
\text { architectural distortion, } \\
\text { increased lamina propria CI, } \\
\text { Paneth cell metaplasia }\end{array}$ & $\begin{array}{l}\text { Ulcerative colitis, primary } \\
\text { sclerosing cholangitis }\end{array}$ \\
\hline 12 & $28(18-34)$ & $14(6-25)$ & $\begin{array}{l}\text { Surface ulceration, Paneth cell } \\
\text { metaplasia }\end{array}$ & Crohn's disease \\
\hline 13 & $20(7-36)$ & $9(3-22)$ & Basal lymphoid aggregate & Constipation \\
\hline 14 & $26(11-40)$ & $10(4-20)$ & Paneth cell metaplasia & Irritable bowel syndrome \\
\hline 15 & $56(22-83)$ & $34(21-48)$ & Epithelial denudation & Lymphocytic colitis \\
\hline $16^{\mathrm{a}}$ & $12(6-30)$ & $6(2-19)$ & Paneth cell metaplasia & $\begin{array}{l}\text { Insulin-dependent diabetes } \\
\text { mellitus, perianal fistula }\end{array}$ \\
\hline 17 & $57(31-82)$ & $40(31-54)$ & Surface epithelial damage & Lymphocytic colitis \\
\hline $18^{\mathrm{a}}$ & $11(3-20)$ & $7(4-16)$ & None & Celiac disease \\
\hline 19 & $47(45-49)$ & $13(12-13)$ & None & Celiac disease \\
\hline 20 & $20(15-23)$ & $8(3-17)$ & Focal cryptitis & Autoimmune enteropathy \\
\hline
\end{tabular}

CI, chronic inflammation; IEL, intraepithelial lymphocytes.

${ }^{\mathrm{a}}$ At least one biopsy in these patients showed more than 20 intraepithelial lymphocytes per 100 colonocytes.

histologic findings included the presence of Paneth cell metaplasia (five patients), neutrophilic cryptitis (four patients), surface epithelial damage (three patients), increased lamina propria chronic inflammation that expanded the lamina propria (three patients), basal lymphoid aggregates (three patients), crypt architectural distortion (three patients; Figure 2), crypt abscesses (two patients; Figure 3), surface epithelial denudation (two patients), ulceration (two patients), and surface epithelial apoptotic debris (one patient). Two patients had the simultaneous presence of neutrophilic cryptitis, crypt abscesses, increased lamina propria chronic inflammation, and crypt architectural distortion.

The findings in concurrently procured biopsies of the terminal ileum and duodenum were also analyzed. In the thirteen patients in whom duodenal biopsies were available, biopsies from two patients showed histologic changes consistent with celiac disease, including variable villous atrophy, crypt hyperplasia, and intraepithelial lymphocytosis (average 37 and 45 intraepithelial lymphocytes per 100 enterocytes, respectively). One additional patient, who was diagnosed with ulcerative colitis, was found to have up to 38 lymphocytes per 100 enterocytes with otherwise normal villous architecture; the remaining duodenal biopsies were histologically unremarkable. Review of 12 patients' available ileal biopsies revealed that all patients showed less than 20 intraepithelial lymphocytes per 100 enterocytes (average 12.2 intraepithelial lymphocytes per 100 enterocytes); however, one patient (no. 9) showed mild acute ileitis (rare neutrophils at the tips of villi), and two patients showed mild villous atrophy (mild decrease in villous height compared with crypt depth).

\section{Clinical Correlation}

The mean clinical follow-up period after biopsy averaged 14 months (range 1-48 months). Despite the wide age range in the cohort, no particular diseases were associated with the neonatal, infant, childhood, or teenage years. The final clinical diagnosis in four patients was inflammatory bowel disease. Two patients were found to have Crohn's disease, with biopsies in one patient showing focal ulceration and Paneth cell metaplasia, and colonic intraepithelial lymphocytosis as the 
a

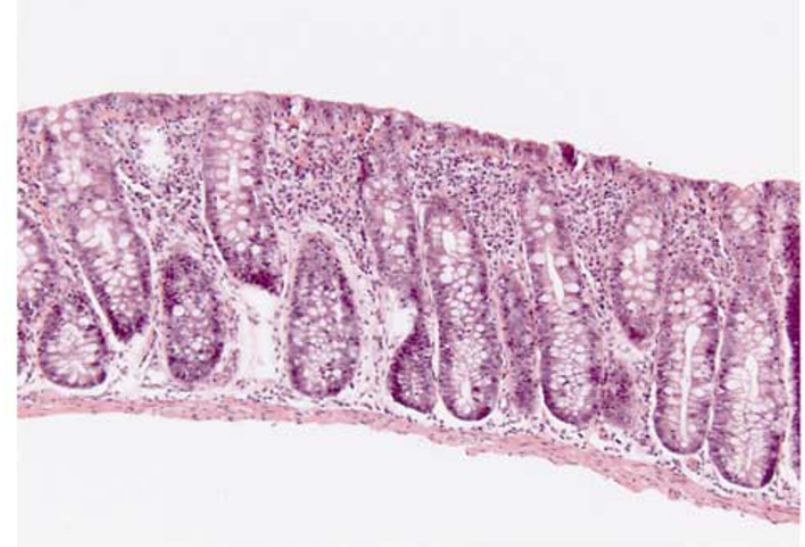

b

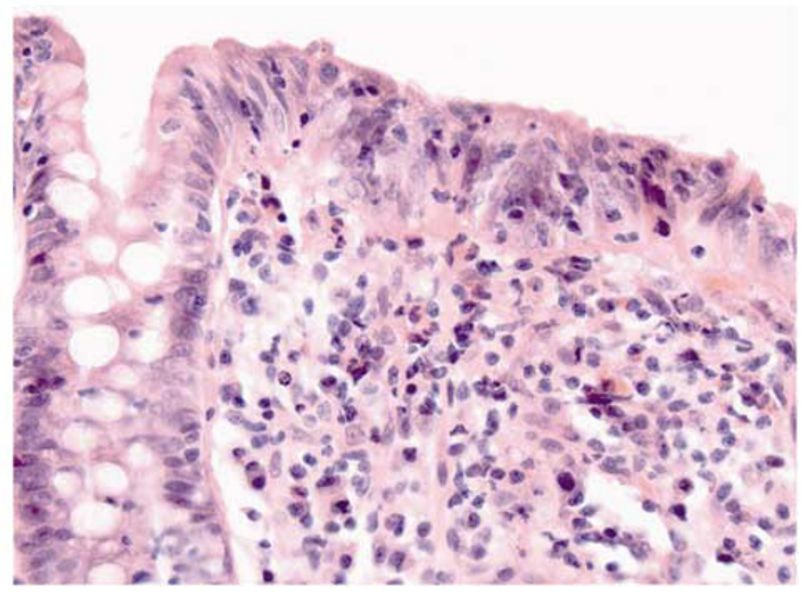

Figure 1 A representative low-power $(\mathbf{a}$; H\&E, $\times 40)$ photograph showing intact crypt architecture without increased lamina propria inflammation. At higher power $(\mathbf{b}$; H\&E, $\times 200)$, intraepithelial lymphocytosis is the only significant histologic finding. This patient was diagnosed with lymphocytic colitis.

only histologic finding in the other. Two patients were diagnosed with ulcerative colitis, with both patients' biopsies demonstrating marked cryptitis, crypt abscesses, architectural distortion, and expanded chronic inflammation in the lamina propria. There was clinical suspicion of Crohn's disease in patient 16 with a perianal fistula; however, she was lost to follow up before a definitive diagnosis was made. Two patients were found to have celiac disease, supported by positive tissue transglutaminase, anti-gliadin, and/or anti-endomysial antibodies and by typical findings in duodenal mucosal biopsies. Lymphocytic colitis was diagnosed in three patients who had chronic watery diarrhea, normal colonic mucosa at endoscopy, and a lack of another apparent etiology. Allergic colitis was the clinical diagnosis in one patient, with high serum IgE levels, peripheral eosinophilia; positive radioallergosorbent test for wheat, and positive skin prick testing; however, this patient did not show significantly increased eosinophils in any biopsy. This patient was also being treated with clarithromycin,

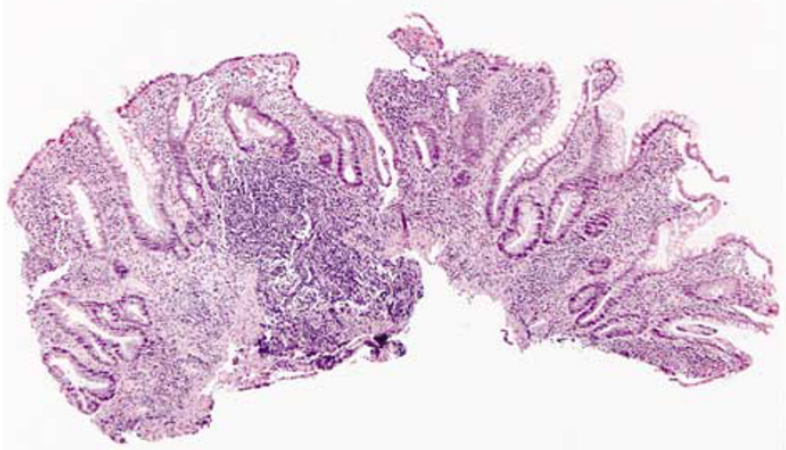

b

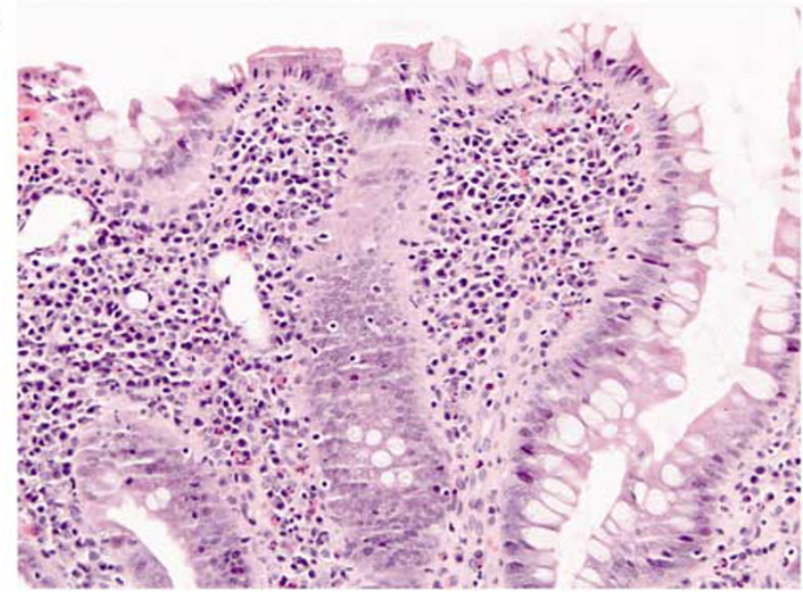

Figure 2 (a) This low-power $(H \& E, \times 40)$ photograph shows abnormal crypt architecture with branching crypts, basal inflammation, and lamina propria that is expanded by chronic inflammatory cells. A higher power photograph (b; H\&E, $\times 200)$ shows increased intraepithelial lymphocytes, especially in the crypts. The final diagnosis in this patient was ulcerative colitis.

amoxicillin, bismuth subsalicylate, and omeprezole for $H$. pylori gastritis at the time of biopsy. Patient 7 had a documented history of Clostridium difficile colitis and was treated with metronidazole before the endoscopy and biopsy that showed colonic intraepithelial lymphocytosis. The endoscopy on this patient showed only mild erythema without pseudomembrane formation; thus, the cause of the patient's colonic intraepithelial lymphocytosis was presumed to be post-infectious in nature. Three patients had severe multisystem autoimmune disease including autoimmune enteropathy. Finally, six study patients were found to have other diseases, including perianal abscess, perianal fistula, idiopathic constipation, Hirschsprung's disease, and irritable bowel syndrome in which colonic intraepithelial lymphocytosis was seen as the only histologic abnormality.

The site of the intraepithelial lymphocytosis within the crypt versus surface epithelium did not correlate with the final clinical diagnosis. Furthermore, the presence of other inflammatory 


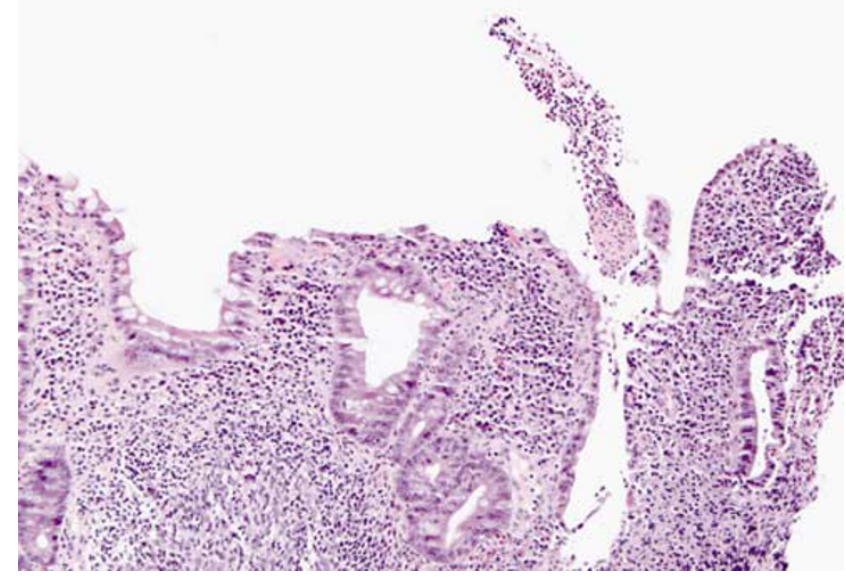

Figure 3 In addition to crypt architecture irregularity, this case showed a crypt abscess (H\&E, $\times 40)$. Other biopsies from this patient showed increased intrapepithelial lymphocytes. The final diagnosis in this patient was ulcerative colitis.

or metaplastic changes did not correlate with the final clinical diagnosis, except in the cases of idiopathic inflammatory bowel disease.

\section{Discussion}

In this report, we describe the clinicopathologic associations of colonic intraepithelial lymphocytosis in a cohort of 20 symptomatic pediatric patients undergoing endoscopy and biopsy. To our knowledge, this is the first description of the significance of increased colonic intraepithelial lymphocytes presented as a retrospective pediatric case series in the English literature.

Like adults, the finding of colonic intraepithelial lymphocytosis in our cohort of pediatric patients was associated with lymphocytic colitis, celiac disease, resolving infectious colitis, and possibly drug-induced colitis. ${ }^{7-9}$ However, other diseases more commonly seen in the pediatric population are also noted to be associated with colonic intraepithelial lymphocytosis, most notably autoimmune enteropathy.

Autoimmune enteropathy rarely presents in adulthood,,$^{10}$ but more typically manifests in infancy or early childhood as a cause of intractable diarrhea. ${ }^{11-14}$ Increased IELs do occur in a subset of patients with autoimmune enteropathy, which typically appears as a destructive acute inflammatory infiltrate with villous loss that may accompany the absence of goblet and/or Paneth cells. ${ }^{10,15}$

Another novel finding in our series is the relative abundance of cases diagnosed as lymphocytic colitis. Lymphocytic colitis is defined as a diarrheal illness that manifests as profuse watery diarrhea in the context of a normal endoscopic appearance which usually occurs in adults during the 4-7th decade. ${ }^{8}$ Histologically, colonic biopsies show intraepithelial lymphocytosis, lamina propria expansion by a predominantly lymphoplasmacytic infiltrate, and normal crypt architecture. ${ }^{8}$ Using these criteria, lymphocytic colitis was found in three of our cases. The literature on pediatric lymphocytic colitis is relatively scant. The largest series, by Mashako et al, ${ }^{16}$ describes a series of five patients with 'microscopic colitis'; the illustrations in this report are diagnostic of lymphocytic colitis. The clinical presentation of the pediatric patients in the report by Matshako et al is quite similar to the lymphocytic colitis cases in our series. Thus, lymphocytic colitis should be recognized as an uncommon cause of chronic diarrheal illness in children; interestingly, there were no cases of collagenous colitis in our series, though there are few reports of pediatric collagenous colitis in the literature. ${ }^{17-19}$

Two of the patients in our series were diagnosed with celiac disease. The association of colonic intraepithelial lymphocytosis and celiac disease is well described, ${ }^{6,9}$ and is always in the differential diagnosis of lymphocytic colitis when diagnosed in adults. As such, when colonic intraepithelial lymphocytosis is found in the pediatric population in the absence of any other histologic findings, celiac disease should always be raised as a diagnostic possibility.

Another major finding in this report is the association of colonic intraepithelial lymphocytosis with idiopathic inflammatory bowel disease. In prototypical cases, biopsies of the colon and/or small intestine show a combination of crypt architecture disarray and acute inflammatory changes including intraepithelial neutrophils, crypt abscesses, and/or ulceration. ${ }^{20}$ However, a small number of patients presenting with idiopathic inflammatory bowel disease, typically Crohn's disease, may present with increased intraepithelial lymphocytes as the only histologic finding, as was observed in one of the four patients diagnosed with idiopathic inflammatory bowel disease. ${ }^{21}$ Three of our patients showed increased intraepithelial lymphocytes in combination with typical findings of inflammatory bowel disease, which has been observed previously. ${ }^{6,21}$

We are aware that changes suggestive of idiopathic inflammatory bowel disease, including crypt architecture distortion, acute crypt inflammation, and Paneth cell metaplasia have been described as part of the histologic spectrum of lymphocytic colitis in the adult population. ${ }^{22,23}$ However, all of the patients with these changes, in addition to colonic intraepithelial lymphocytosis, proved to have idiopathic inflammatory bowel disease within our follow-up period.

Owing to the recent history of treated $C$. difficile colitis, and an endoscopy that showed minimal findings, one patient's colonic intraepithelial lymphocytosis was thought to be due to post-infectious changes. It has been postulated that increased 
colonic intraepithelial lymphocytes may be present as part of an active infection, a slowly resolving infectious process, or a persistent inflammatory response to a remote infection. ${ }^{24,25}$ However, a specific association of $C$. difficile infection and colonic intraepithelial lymphocytosis has yet to be well established.

One patient had clinical findings that strongly suggested an allergic process. However, examination of the patient's colonic mucosal biopsies only showed a modest colonic intraepithelial lymphocytosis without any other findings such as increased eosinophilic infiltrates. However, this patient was being treated with multiple antimicrobials, including amoxicillin, and a proton-pump inhibitor as treatment for $H$. pylori gastritis. Both protonpump inhibitors and penicillin derivatives are known causes of colonic intraepithelial lymphocytosis; ${ }^{26,27}$ thus, the cause of this patient's intraepithelial lymphocytosis is presumed to be drug induced.

To our knowledge, this is the first cohort of pediatric patients with colonic intraepithelial lymphocytosis presented in the English literature. As a retrospective study, however, the strength of our conclusions is somewhat limited. In addition, the average follow-up time of 14 months potentially limits the accuracy of the final clinical diagnoses and may explain the lack of apparent disease associations in some of the patients. Therefore, the subject of pediatric colonic intraepithelial lymphocytosis would certainly benefit from a prospective study and validation in the future.

In summary, colonic mucosal biopsies in the pediatric population that show intraepithelial lymphocytosis without other significant other histologic findings have diverse clinical associations, most of which parallel the adult population. However, colonic intraepithelial lymphocytosis is also seen in various pediatric diseases not typically seen in adults.

\section{Acknowledgement}

We thank Dr Harvey Goldman for his critical evaluation of the paper.

\section{Disclosure/conflict of interest}

All authors declared no conflicts of interest.

\section{References}

1 Marsh MN, Crowe PT. Morphology of the mucosal lesion in gluten sensitivity. Baillieres Clin Gastroenterol 1995;9:273-293.

2 Cutz E, Sherman PM, Davidson GP. Enteropathies associated with protracted diarrhea of infancy: clinicopathological features, cellular and molecular mechanisms. Pediatr Pathol Lab Med 1997;17: 335-368.

3 Kleinman RE. Milk protein enteropathy after acute infectious gastroenteritis: experimental and clinical observations. J Pediatr 1991;118:S111-S115.

4 Mavromichalis J, Brueton MJ, McNeish AS, et al. Evaluation of the intraepithelial lymphocyte count in the jejunum in childhood enteropathies. Gut 1976; 17:600-603.

5 Antonioli DA. Celiac disease: a progress report. Mod Pathol 2003;16:342-346.

6 Wang N, Dumot JA, Achkar E, et al. Colonic epithelial lymphocytosis without a thickened subepithelial collagen table: a clinicopathologic study of 40 cases supporting a heterogeneous entity. Am J Surg Pathol 1999;23:1068-1074.

7 Fine KD, Lee EL, Meyer RL. Colonic histopathology in untreated celiac sprue or refractory sprue: is it lymphocytic colitis or colonic lymphocytosis? Hum Pathol 1998;29:1433-1440.

8 Lazenby AJ, Yardley JH, Giardiello FM, et al. Lymphocytic ('microscopic') colitis: a comparative histopathologic study with particular reference to collagenous colitis. Hum Pathol 1989;20:18-28.

9 Wolber R, Owen D, Freeman H. Colonic lymphocytosis in patients with celiac sprue. Hum Pathol 1990;21: 1092-1096.

10 Akram S, Murray JA, Pardi DS, et al. Adult autoimmune enteropathy: Mayo Clinic Rochester experience. Clin Gastroenterol Hepatol 2007;5: 1282-1290.

11 Bousvaros A, Leichtner AM, Book L, et al. Treatment of pediatric autoimmune enteropathy with tacrolimus (FK506). Gastroenterology 1996;111:237-243.

12 Savage MO, Mirakian R, Wozniak ER, et al. Specific autoantibodies to gut epithelium in two infants with severe protracted diarrhoea. J Pediatr Gastroenterol Nutr 1985;4:187-195

13 Hill SM, Milla PJ, Bottazzo GF, et al. Autoimmune enteropathy and colitis: is there a generalised autoimmune gut disorder? Gut 1991;32:36-42.

14 Rogahn D, Smith CP, Thomas A. Autoimmune enteropathy with goblet-cell antibodies. JR Soc Med 1999;92:311-312.

15 Cuenod B, Brousse N, Goulet O, et al. Classification of intractable diarrhea in infancy using clinical and immunohistological criteria. Gastroenterology 1990; 99:1037-1043.

16 Mashako MN, Sonsino E, Navarro J, et al. Microscopic colitis: a new cause of chronic diarrhea in children? J Pediatr Gastroenterol Nutr 1990;10: 21-26.

17 Camarero C, Leon F, Colino E, et al. Collagenous colitis in children: clinicopathologic, microbiologic, and immunologic features. J Pediatr Gastroenterol Nutr 2003;37:508-513.

18 Gremse DA, Boudreaux CW, Manci EA. Collagenous colitis in children. Gastroenterology 1993;104: 906-909.

19 Yardley JH, Lazenby AJ, Kornacki S. Collagenous colitis in children. Gastroenterology 1993;105: 647-648.

20 Antonioli DA. Pediatric inflammatory bowel disease. Pediatr Dev Pathol 2005;8:2-19.

21 Goldstein NS, Gyorfi T. Focal lymphocytic colitis and collagenous colitis: patterns of Crohn's colitis? Am J Surg Pathol 1999;23:1075-1081. 
22 Ayata G, Ithamukkala S, Sapp H, et al. Prevalence and significance of inflammatory bowel disease-like morphologic features in collagenous and lymphocytic colitis. Am J Surg Pathol 2002;26:1414-1423.

23 Shaz BH, Reddy SI, Ayata G, et al. Sequential clinical and histopathological changes in collagenous and lymphocytic colitis over time. Mod Pathol 2004;17:395-401.

24 Bryant DA, Mintz ED, Puhr ND, et al. Colonic epithelial lymphocytosis associated with an epidemic of chronic diarrhea. Am J Surg Pathol 1996;20:1102-1109.

25 Olesen M, Eriksson S, Bohr J, et al. Lymphocytic colitis: a retrospective clinical study of 199 Swedish patients. Gut 2004;53:536-541.

26 Thomson RD, Lestina LS, Bensen SP, et al. Lansoprazoleassociated microscopic colitis: a case series. Am J Gastroenterol 2002;97:2908-2913.

27 Giardiello FM, Hansen III FC, Lazenby AJ, et al. Collagenous colitis in setting of nonsteroidal antiinflammatory drugs and antibiotics. Dig Dis Sci 1990;35:257-260. 